\title{
Seasonal effects of central leptin infusion on secretion of melatonin and prolactin and on SOCS-3 gene expression in ewes
}

\author{
D A Zieba, M Szczesna, B Klocek-Gorka, E Molik, T Misztal ${ }^{1}$, G L Williams ${ }^{2}$, K Romanowicz ${ }^{1}$, E Stepien ${ }^{3}$, \\ D H Keisler ${ }^{4}$ and $\mathbf{M}$ Murawski
}

Department of Sheep and Goat Breeding, University of Agriculture, 30-059 Krakow, Poland

${ }^{1}$ Department of Endocrinology, Institute of Animal Physiology and Nutrition, 05-110 Jablonna, Poland

${ }^{2}$ Animal Reproduction Laboratory, Texas A\&M University Agricultural Research Station, Beeville, 78102 Texas, USA

${ }^{3}$ Independent Laboratory of Molecular Biology and Research, John Paul II Hospital in Krakow, 31-202 Krakow, Poland

${ }^{4}$ Department of Animal Science, University of Missouri, Columbia, 65211 Missouri, USA

(Correspondence should be addressed to D A Zieba; Email: rzzieba@cyf-kr.edu.pl)

\begin{abstract}
Recent studies have demonstrated photoperiodic changes in leptin sensitivity of seasonal mammals. Herein, we examined the interaction of season (long days (LD) versus short days (SD)) and recombinant ovine leptin (roleptin) on secretion of melatonin and prolactin (PRL) and on mRNA expression of suppressor of cytokine signaling-3 (SOCS-3) in the medial basal hypothalamus (MBH) in sheep. Twenty-four Polish Longwool ewes, surgically fitted with third ventricle (IIIV) cannulas, were utilized in a replicated switchback design involving 12 ewes per season. Within-season and replicate ewes were assigned randomly to one of three treatments (four ewes/treatment) and infused centrally three times at 0,1 and $2 \mathrm{~h}$ beginning at sunset. Treatments were 1) control, Ringer-Locke buffer; 2) L1, roleptin, $0.5 \mu \mathrm{g} / \mathrm{kg} \mathrm{BW}$; and 3) $\mathrm{L} 2$, roleptin, $1 \cdot 0 \mu \mathrm{g} / \mathrm{kg} \mathrm{BW}$. Jugular blood samples were collected at 15-min intervals beginning immediately before the start of infusions and continued for $6 \mathrm{~h}$. At the end of blood sampling, a washout period of at least 3 days elapsed before ewes were re-randomized and treated with one of the treatments described above (four
\end{abstract}

ewes/treatment). Ewes were then killed and brains were collected for $\mathrm{MBH}$ processing. Leptin treatments increased $(P<0 \cdot 001)$ circulating leptin concentrations compared with controls during both seasons in a dose-dependent manner. Overall, mean plasma concentrations of melatonin were greater $(P<0 \cdot 001)$ during LD than SD. However, leptin treatments increased melatonin concentrations during $\mathrm{SD}$ in a dosedependent manner and decreased it during LD. Similarly, plasma concentrations of PRL were greater $(P<0 \cdot 001)$ during $\mathrm{LD}$ than SD. However, unlike changes in melatonin, circulating PRL decreased $(P<0 \cdot 001)$ in response to leptin during LD. Semiquantitative PCR revealed that leptin increased $(P<0 \cdot 001)$ SOCS-3 expression in the MBH region during LD in a dosedependent manner. Data provide evidence that secretion of photoperiodic hormones such as melatonin and PRL are inversely regulated by leptin during SD and LD. However, the increase in expression of SOCS-3 in the $\mathrm{MBH}$ during LD compared with SD fails to fully explain these effects.

Journal of Endocrinology (2008) 198, 147-155

\section{Introduction}

In temperate latitudes, sheep are seasonal breeders whose reproductive activity is controlled mainly by photoperiod. Nocturnal secretion of pineal-derived melatonin provides information about day length, but neither the target sites for its action in the brain nor the neuropeptide circuits engaged by the melatonin signal are well-defined (Lincoln et al. 2006).

Exposure to short days (SD) decreases leptin gene expression and hormone release in adipose tissues of Siberian hamsters, indicating that leptin may be involved in photoperioddependent seasonal adaptations of mammals, independent of food deprivation or overfeeding (Klingenspor et al. 1996, 2000). Recently, our laboratory has shown that recombinant ovine leptin (roleptin) is able to modulate melatonin release by ovine

pineal gland explants in vitro, and that this effect is seasonally dependent (Zieba et al. 2007). In seasonal mammals, melatonin also regulates photoperiodic changes in plasma concentrations of prolactin (PRL) through a melatonin-dependent oscillator located in the pars tuberalis. However, information on the effect of leptin on PRL secretion is meager and conflicting. PRL is an essential hormone for mammary gland development and milk production, and modulates adipose tissue lipid metabolism in adipocytes (Symonds \& Clarke 1998). However, leptin receptors (LR) on lactotrophs are scarce, and leptin infusion into the arcuate nucleus (ARC) and median eminence stimulates PRL secretion. This suggests a control pathway mediated by hypothalamic neurons (Watanobe \& Habu 2002), although direct stimulation of PRL secretion from pituitary explants is possible (Accorsi et al. 2007). 
If the major control of seasonal changes to leptin sensitivity is at the hypothalamic level, how is this effect mediated. Although several potential mechanisms to account for this state have been proposed (Levin et al. 2004, Münzberg et al. 2005), the one receiving the most attention has been the inhibition of intracellular leptin signaling by suppressors of cytokine signaling-3 (SOCS-3), which can occur within leptin's primary targets in the ARC (Adam \& Mercer 2004). Studies in the Siberian hamster (Phodopus sungorus, Tups et al. 2004) have demonstrated that reduced SOCS-3 activity during short SD contributes to the increased sensitivity to leptin and, conversely, that increased activity of SOCS-3 signaling contributes to the relative leptin insensitivity seen in long days (LD). Changes in hypothalamic sensitivity to leptin in sheep at different times of the year have been reported by two re-search groups (Clarke et al. 2001, Adam et al. 2003, 2006). However, those studies mainly investigated the photoperiodic regulation of appetite and reproductive axes.

The work reported herein was designed to determine how leptin modulates melatonin and PRL secretion in mature sheep during natural LD and SD in order to better understand the interplay between three hormones known to be under the influence of photoperiod. The second aim was to accumulate preliminary information on the relationship between SOCS-3 gene expression in the $\mathrm{MBH}$ and leptin-mediated effects.

\section{Materials and Methods}

All animal-related procedures used in these studies were approved by the Local Agricultural Animal Care and Use Committee of Krakow (protocol no. 25/OP/2005).

Studies were carried out at the Experiment Station in the Department of Sheep and Goat Breeding, Agricultural University of Krakow (longitude $19^{\circ} 57^{\prime}$ E, latitude $50^{\circ} 04^{\prime} \mathrm{N}$ ). Twenty-four female Polish Longwool sheep, a breed that exhibits strong reproductive seasonality, were used. Animals were 2-3 years of age, weighed $60 \pm 5 \mathrm{~kg}$, and were housed in individual pens in natural photoperiodic and thermoperiodic conditions. Sheep were in good body condition $(\mathrm{BCS}=3)$ on a 1-5 scale (Russel et al. 1969), and were fed twice daily at 0700 and $1600 \mathrm{~h}$ a diet formulated to provide $100 \%$ of the National Research Institute of Animal Production recommendations for maintenance (Norms 1993). Water was available ad libitum.

\section{Neuroendocrine model}

In a previous experiment reported from this laboratory, we demonstrated that the ability of roleptin to modulate pineal gland melatonin secretion was dependent on day length when tissues were collected from sexually mature female sheep kept under natural photoperiod (Zieba et al. 2007). In that experimental model, the secretion of melatonin from ovine pineal glands was negatively responsive to leptin during LD, whereas leptin-stimulated melatonin secretion during
SD (Zieba et al. 2007). Therefore, for the present study, we measured melatonin secretion directly after roleptin was infused into the third ventricle (IIIV).

\section{Procedures}

Twenty-four female mature sheep fasted for $24 \mathrm{~h}$ were fitted surgically with IIIV cannulas according to the methodology of Traczyk \& Przekop (1963). The location and function of the cannulas were verified by the continuous flow of cerebrospinal fluid (CSF). A period of at least 3 weeks was allowed for sheep to recover from neurosurgery.

Before the study began, ewes were placed frequently in individual carts to familiarize them with the experimental conditions. All experiments started at sunset with 12 ewes selected randomly during LD (March, April \& May) and an additional 12 ewes during SD (September, October, and November). During LD, ewes were anovulatory and expressed no signs of estrus. During SD, estrous cycles were synchronized using a 14-day treatment with intravaginal progestogen-impregnated sponges $(40 \mathrm{mg}$ fluorogestone acetate, FGA, Chronogest; Intervet International, Boxmeer, The Netherlands). Ewes were also injected with a single dose of $500 \mathrm{IU}$ of pregnant mares serum gonadotropin i.m. (Serogonadotropin, Biowet, Drwalew, Poland) on the day of sponge removal. Estrous detection was performed twice daily with an adult ram equipped with an apron. Ewes were presented individually to the male. Estrus was defined as an acceptance of mounting. Experiments were performed when ewes were in the mid-luteal phase (days 7-10) of the oestrous cycle.

In the morning of the day of each experiment, sheep were fitted with jugular catheters for intensive blood sampling. Polyethylene tubing $(70 \mathrm{~mm} ; 0.58$ i.d., $0.96 \mathrm{~mm}$ o.d.; Intramedic Clay Adams Brand, Becton Dickinson, Sparks, MD, USA) was inserted, using aseptic technique, through each IIIV guide cannula so that the distal end projected $3-5 \mathrm{~mm}$ past the end of the cannula and into the ventricle. The proximal end of the tubing extended $\sim 5-10 \mathrm{~mm}$ above the tip of the guide cannula. Tubing was adjusted until CSF flowed easily using a blunt $22 \mathrm{G}$ needle and tuberculin syringe. The tubing was then plugged until later use.

In the afternoon of the day of each experiment, ewes were assigned randomly to one of three groups ( $n=4$ /group), and then ewes were placed into carts, and CSF flow was confirmed. Recombinant oleptin for use in the experiment was obtained from Ray Biotech, Inc. (Norcross, GA, USA). Treatments consisted of 1) control, Ringer-Locke buffer ( $\mathrm{pH}$ $7 \cdot 4)$; 2) L1, low dose of exogenous leptin $(0.5 \mu \mathrm{g} / \mathrm{kg} \mathrm{BW})$; and 3) L2, high dose of roleptin $(1.0 \mu \mathrm{g} / \mathrm{kg} \mathrm{BW})$ in a switchback design such that four ewes from each group received one of the three treatments (control, L1, or L2) centrally into IIIV in random order $\sim 2$ weeks apart (Fig. 1A). With 12 ewes per season, this involved three replications. The dose of leptin for i.c.v. study was determined from our previous experience (Amstalden et al. 2002, Zieba et al. 
A March/September

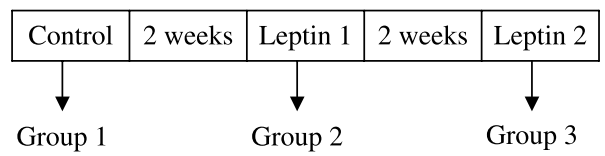

April/October

\begin{tabular}{|c|c|c|c|c|}
\hline Control & 2 weeks & Leptin 1 & 2 weeks & Leptin 2 \\
\hline \multirow{\text{Group2}}{}{} & & & & \\
& & Group 3 & & Group 1
\end{tabular}

May/November

\begin{tabular}{|c|c|c|c|c|}
\hline Control & 2 weeks & Leptin 1 & 2 weeks & Leptin 2 \\
\hline$\downarrow$ & & $\downarrow$ & & \\
Group 3 & & Group 1 & & Group 2
\end{tabular}

B

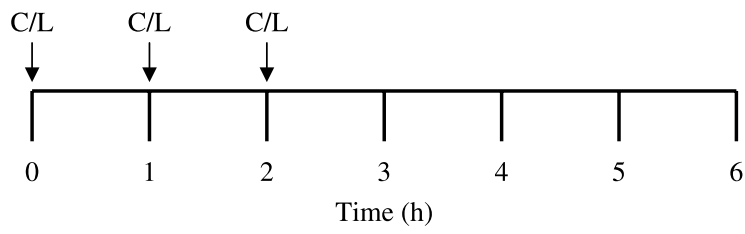

$5 \mathrm{ml}$ of blood collected every 15 minutes and replaced with saline

Figure 1 (A and B) Timeline for experimental procedures. 12 ewes were assigned randomly to one of three groups ( $n=4 /$ group) during long-day (LD; March, April, May) and short-day (SD; September, October, and November) photoperiods. Treatments consisted of (1) control, Ringer-Locke buffer; (2) L1, low dose of exogenous leptin $(0.5 \mu \mathrm{g} / \mathrm{kg} \mathrm{BW})$; and (3) L2, high dose of roleptin ( $1.0 \mu \mathrm{g} / \mathrm{kg} \mathrm{BW})$ in a switchback design such that four ewes from each group received one of the three treatments (control, L1, or L2) centrally into IIIV in random order $\sim 2$ weeks apart. Arrows indicate central treatments with roleptin (L) or Ringer-Locke buffer (control, C) at 0,1 , and $2 \mathrm{~h}$ of the 6-h experiment.

2003a,b, 2004) and both theoretical calculations and a published study of i.c.v. injection in sheep (Adam et al. 2006). Blood samples (5 ml) were collected at 15-min intervals for $6 \mathrm{~h}$ beginning immediately before the first infusion at sunset and continued later on under the red lights (Fig. 1B).

The blood samples were dispensed into tubes containing $150 \mu \mathrm{l}$ of a solution containing heparin $(10000 \mathrm{IU} / \mathrm{ml})$ and $5 \%(\mathrm{w} / \mathrm{v})$ EDTA and placed on ice immediately. Plasma was separated by centrifugation and stored at $-20{ }^{\circ} \mathrm{C}$ until melatonin, PRL, and leptin analyses.

At the end of the blood sampling experiments (June for LD season and December for SD season), a washout period of $\sim 3$ days followed, whereupon ewes were re-randomized and the infusion treatments described above were repeated. One hour after the end of infusions, ewes were killed humanely by captive bolt stunning. Brains were collected so that the infundibulum remained intact. Thus, the $\mathrm{MBH}$ was harvested by removing a tissue block encompassing the hypothalamic-infundibular complex, followed by transection into two halves. An anterior coronal cut was made $\sim 3-5 \mathrm{~mm}$ rostral from the optic chiasm and a posterior coronal cut was made, which included about one-third of the mamillary body. A longitudinal cut parallel to the ventral surface of the brain $\sim 2-3 \mathrm{~cm}$ dorsal to anterior commissure followed. Tissue was frozen immediately on dry ice for storage at $-70{ }^{\circ} \mathrm{C}$.

\section{RIA}

RIA for melatonin Melatonin was assayed in unextracted plasma according to the method of Fraser et al. (1983) and modified by Misztal et al. (1996). Ovine anti-melatonin serum (AB/S/01, Stockgrand Ltd, Surrey, UK), synthetic melatonin (Sigma Chemical Co.), and (O-methyl- $\left.{ }^{3} \mathrm{H}\right)$-melatonin (Amersham Biosciences) served as the first antibody, reference standard, and tracer respectively. Melatonin-free plasma for curve calibration and blanks were obtained from sheep and stripped of endogenous melatonin using activated charcoal (Norit-A; Sigma Chemical Co). The range of the calibration curve was from $15 \cdot 6$ to $1000 \mathrm{pg} / \mathrm{ml}$ and the working dilution of the first antibody was 1:4000. Bound and free fractions were separated after overnight incubation at $4{ }^{\circ} \mathrm{C}$ using dextrancoated charcoal. Sensitivity of the assay was $16 \cdot 8 \pm 8 \cdot 0 \mathrm{pg} / \mathrm{ml}$ and the intra- and interassay coefficients of variations were $10 \cdot 5$ and $13 \cdot 2 \%$ respectively.

RIA for PRL Plasma concentrations of PRL were assayed by the double antibody method using anti-ovine PRL and anti-rabbit- $\gamma$-globulin antisera according to Wolinska et al. (1977). Assay sensitivity was $2 \mathrm{ng} / \mathrm{ml}$ and intra- and interassay coefficients of variations were $9 \%$ and $12 \%$ respectively.

RIA for leptin Circulating concentrations of leptin were determined using a highly specific ovine leptin RIA (Delavaud et al. 2000). Determinations of circulating concentrations of leptin were performed in samples collected every $15 \mathrm{~min}$ for the first $4 \mathrm{~h}$ and every $30 \mathrm{~min}$ for the following $2 \mathrm{~h}$ of the experiment. The intra-assay coefficient of variation of leptin assay was $3 \cdot 2 \%$.

SOCS-3 mRNA expression in MBH Semi-quantitative expression of SOCS-3 mRNA in the $\mathrm{MBH}$ of the brain was performed by RT-PCR. Total RNA was prepared using TRIzol reagent (Invitrogen Corporation) according to the manufacturer's instructions. Total RNA $(1 \mu \mathrm{g})$ was reverse transcribed to cDNA using Moloney murine leukemia virus (MMLV) Reverse Transcriptase and Oligo(dT) Primer (Advantage RT-for-PCR Kit; Clontech) using a UNO II Thermocycler (Biometra, Göttingen, Germany). An initial denaturation step was performed for $5 \mathrm{~min}$ at $95^{\circ} \mathrm{C}$ before first-strand synthesis at $42{ }^{\circ} \mathrm{C}$ for $60 \mathrm{~min}$. The reaction was terminated by heating to $94{ }^{\circ} \mathrm{C}$ for $5 \mathrm{~min}$. Each PCR 
was performed by the Titanium Taq PCR Kit (Clontech). Primers were P1 $5^{\prime}$-CCAGCCTGCGCCTCAA- $3^{\prime}$ and P2 $5^{\prime}$-CTTGCGCACTGCGTTCAC-3' (corresponding to the bovine SOCS-3 gene; GenBank accession number NM_174466) for amplification of the $68 \mathrm{bp}$ fragment. Primers for the reference gene were $5^{\prime}$-CCAACGGCTCCCAGTTCTT-3' and 5'-ACTACGTGCTTCCCATCCAAA-3' (corresponding to bovine cyclophiline; GenBank accession number D14074) for amplification of the $64 \mathrm{bp}$ fragment. Amplification was performed by a tri-iodothyronine Thermocycler (Biometra) under the following conditions: $94{ }^{\circ} \mathrm{C}$ for $5 \mathrm{~min}$ followed by 36 cycles of $94{ }^{\circ} \mathrm{C}$ for $45 \mathrm{~s}, 55^{\circ} \mathrm{C}$ for $45 \mathrm{~s}$, and $72{ }^{\circ} \mathrm{C}$ for $45 \mathrm{~s}$. Reactions were terminated at $72{ }^{\circ} \mathrm{C}$ for $10 \mathrm{~min}$. The PCR products were separated on a $3 \%$ agarose gel, stained with ethidium bromide, and analyzed using the Dscan Ex. v.3.1.0 program (Scanalytics Inc., La Jolla, CA, USA).

\section{Statistical analysis}

Hormone data were analyzed by the general linear models (GLM) procedure (PROC GLM) of the Statistical Analysis System (SAS 8.1; SAS Institute Inc., Cary, NC, USA). For hormone comparisons, the overall ANOVA included treatment, season, replicate within season, time within season, and all two and three-way interactions as for repeated measures in a switchback design. Significant treatment $X$ season interactions resulted in a within-season model that included treatment, time and treatment $X$ time. Following a significant $F$-test, the Pdiff procedure of SAS was used to contrast means. Content of mRNA in the MDB was evaluated by ANOVA with treatment and season as main effects. Following determination of a significant $F$-value, means were contrasted using Duncan's multiple range test. Differences with $P<0 \cdot 05$ were considered statistically significant. Data are expressed as means \pm s.E.M.

\section{Results}

\section{Hormone data}

In the absence of leptin treatment (control periods), mean circulating concentrations of leptin were greater $(P<0 \cdot 0001)$ during LD than SD $(7 \cdot 64 \pm 0 \cdot 2$ vs $5 \cdot 76 \pm 0 \cdot 1 \mathrm{ng} / \mathrm{ml})$. Intracerebroventricular treatment with roleptin increased $(P<0 \cdot 0001)$ mean concentrations of circulating leptin compared with controls in both seasons in a dose-dependent manner (Fig. 2).

Mean concentrations of melatonin during control periods were greater $(P<0 \cdot 001)$ during LD compared with SD $(61 \cdot 18 \pm 10 \cdot 1$ vs $29 \cdot 66 \pm 10 \cdot 3 \mathrm{pg} / \mathrm{ml}$; Fig. 3). Central roleptin infusions increased mean concentrations of melatonin $(P<0.001)$ during SD in both treatment groups in a dosedependent manner compared with the control (Figs 3 and 4). During LD, roleptin treatment decreased melatonin concentrations $(P<0 \cdot 001)$ in response to both doses of roleptin compared with the control (Figs 3 and 4).

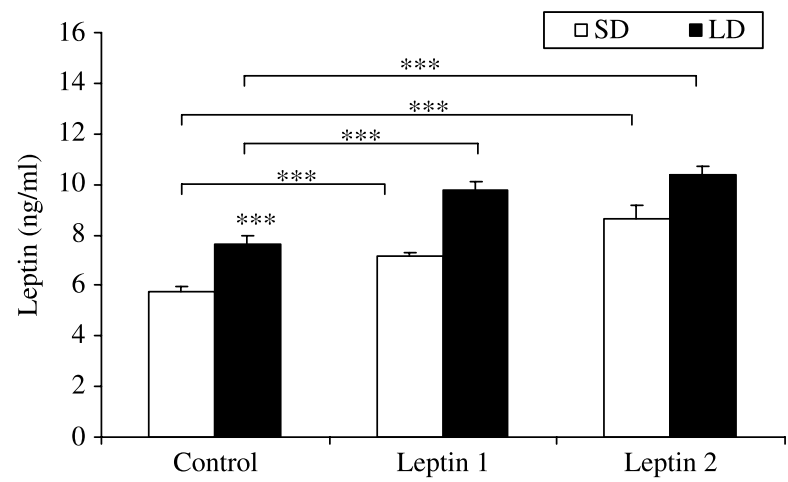

Figure 2 Mean ( \pm S.E.M.) plasma concentrations of leptin in control and leptin-treated ewes during short (SD) and long days (LD). Central infusions of roleptin $(\mathrm{L})$ increased $(P<0 \cdot 0001)$ concentrations of circulating leptin compared with control treatments in both LD and SD seasons. ${ }^{* * *}$ denote difference from control $(P<0 \cdot 001)$.

During LD, overall mean concentrations of PRL in untreated controls were much greater $(P<0 \cdot 001)$ than during $\mathrm{SD}(132 \cdot 28 \pm 19 \cdot 87$ vs $44 \cdot 41 \pm 8 \cdot 27 \mathrm{ng} / \mathrm{ml}$; Fig. 5). Intracerebroventricular infusions of both doses of roleptin decreased mean concentrations of PRL during SD $(P<0 \cdot 001$, Fig. 6). Concentrations of PRL decreased in response to higher and lower dose of roleptin compared with the control in SD.

\section{SOCS-3 gene expression in $\mathrm{MBH}$}

Treatment with roleptin increased $(P<0 \cdot 001)$ SOCS-3 mRNA expression during LD in a dose-dependent manner (Fig. 7) compared with controls. Concentrations of SOCS-3 mRNA in $\mathrm{MBH}$ during LD was almost twice as great $(P<0 \cdot 05)$ in $\mathrm{L} 2$ as in L1. By contrast, roleptin infusion had no effect on SOCS-3 expression during SD (Figs 7 and 8).

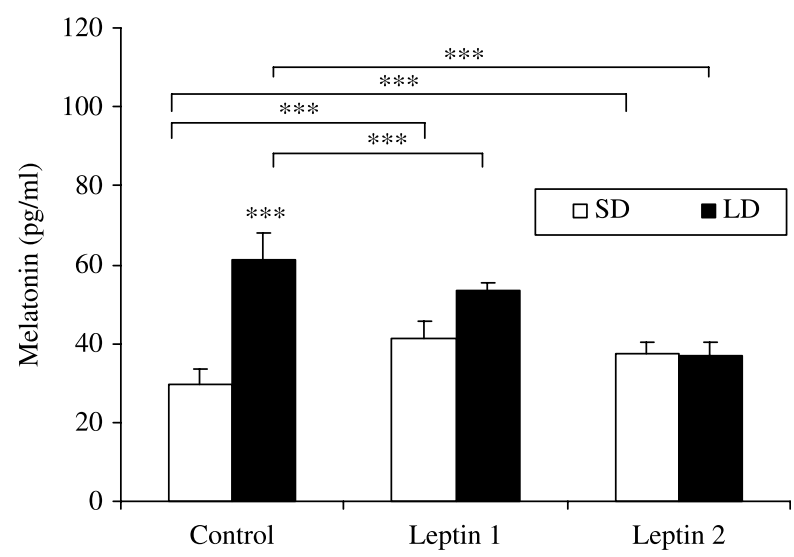

Figure 3 Mean ( \pm S.E.M.) concentrations of melatonin in control and leptin-treated ewes during short- (SD) and long-day (LD) photoperiods. Central roleptin infusions increased mean concentrations of melatonin $(P<0 \cdot 001)$ during SD in both treatment groups (L1 and L2) compared with controls (C). During LD, roleptin decreased melatonin concentrations $(P<0 \cdot 001)$ in leptin-treated sheep compared with controls in a dose-dependent manner. ${ }^{* * *}$ denote difference from control $(P<0 \cdot 001)$. 

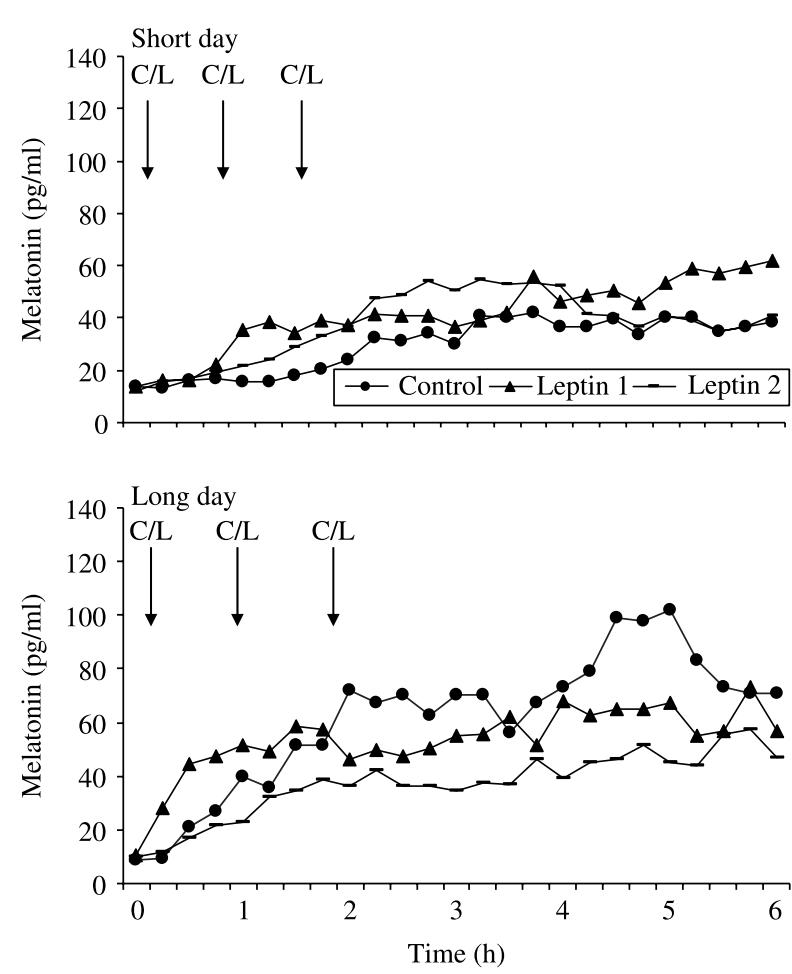

Figure 4 Temporal patterns of circulating melatonin in 15-min samples collected after control or roleptin infusions. Upper panel depicts serum concentrations of melatonin during short days (SD), with mean concentrations of melatonin greater $(P<0 \cdot 001)$ in L1 and L2 compared with controls (C). Lower panel depicts serum concentrations of melatonin during long days (LD) in which mean melatonin concentrations were lower $(P<0 \cdot 001)$ in leptin-treated ewes compared with controls. Arrows indicate Ringer-Locke buffer (control, C) or leptin treatments (L).

\section{Discussion}

The present studies confirmed our previous in vitro observations with pineal explants that exogenous leptin is able to differentially affect melatonin secretion in sheep depending on day length (Zieba et al. 2007). Herein, we report a seasonal switch in sensitivity of the ovine pineal gland to leptin, with stimulatory effects of exogenous leptin on melatonin secretion during SD and inhibitory effects during LD. Interestingly, overall mean concentrations of melatonin in control ewes were markedly greater during LD than SD. Previous reports on endogenous secretion of melatonin in sheep have indicated large inter-individual variability in plasma concentrations of melatonin at night, and this appears to be a rather common mammalian trait (Coon et al. 1999). Circulating concentrations of melatonin in sheep have been shown to range from less than 50 to more than $800 \mathrm{pg} / \mathrm{ml}$, with much less variability observed within animals (Chemineau et al. 2002). Individual variability appears to be under strong genetic control, and originates in part from differences in pineal size and the number of pinealocytes, both of which are correlated strongly with plasma melatonin concentrations

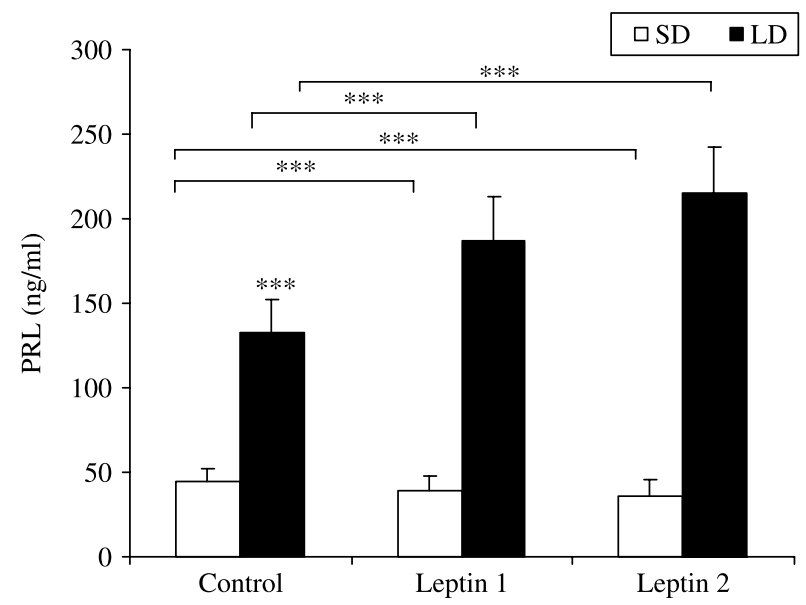

Figure 5 Mean ( \pm S.E.M.) concentrations of prolactin (PRL) in control and leptin-treated ewes during short- (SD) and long-day (LD) photoperiods. Overall, mean concentrations of PRL were greater $(P<0 \cdot 001)$ in controls during LD compared with SD. Central infusions of roleptin (both doses) decreased $(P<0 \cdot 001)$ mean concentrations of PRL slightly during SD, and increased $(P<0 \cdot 001)$ $P R L$ in response to two doses compared with controls during LD. ***denote difference from control $(P<0 \cdot 001)$.
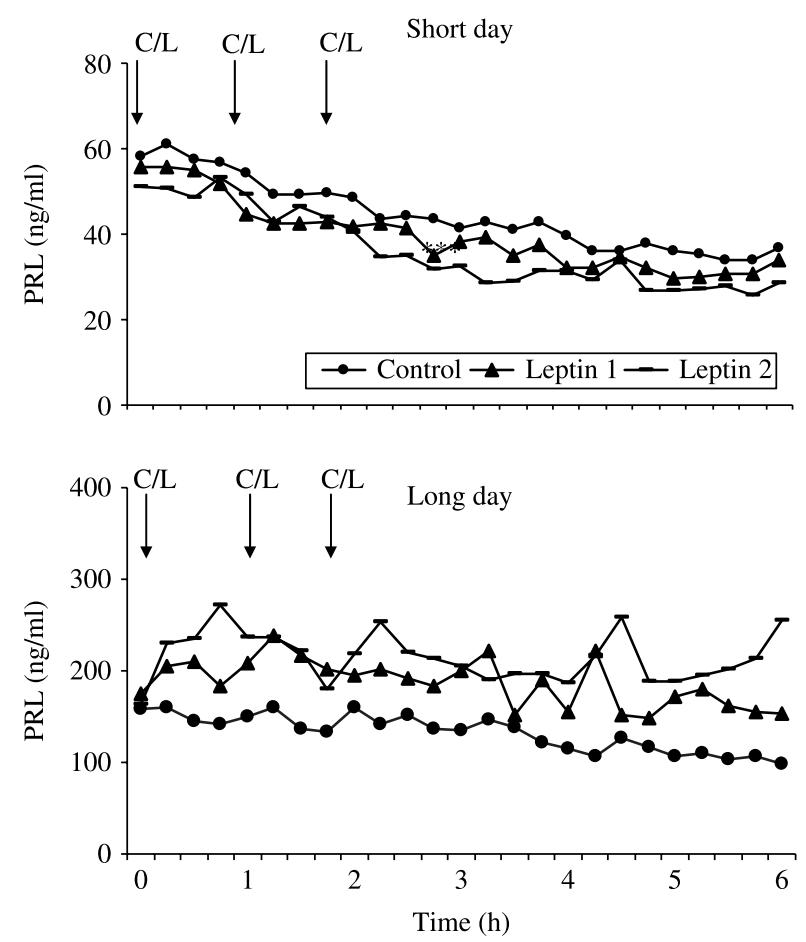

Figure 6 Mean concentrations of circulating prolactin in 15-min samples collected after control or roleptin infusions. Upper panel depicts serum concentrations of prolactin during the short days (SD), with mean concentrations of prolactin less $(P<0 \cdot 001)$ in L1 and L2 treatment groups compared with controls $(C)$. Lower panel depicts serum concentrations of prolactin during long days (LD) in which mean prolactin concentrations were increased $(P<0 \cdot 001)$ by roleptin compared with controls. Arrows indicate Ringer-Locke buffer (control, C) or leptin treatments (L). 


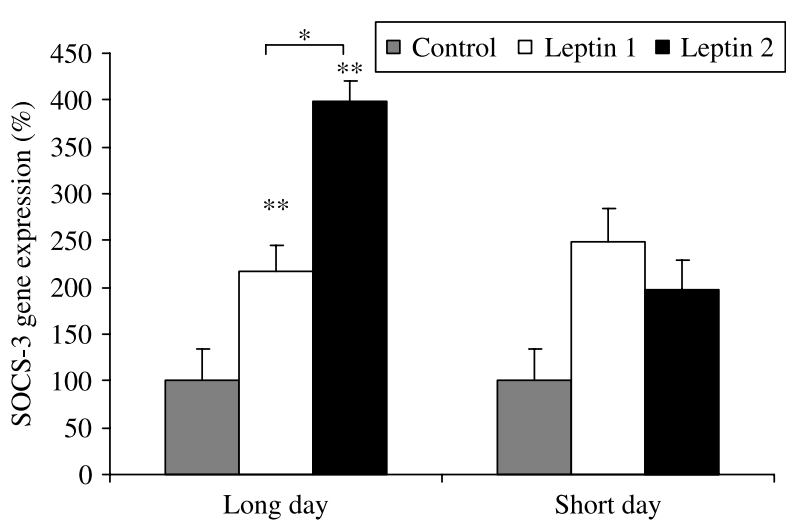

Figure 7 SOCS-3 mRNA expression (\% of control) in medial basal hypothalamus $(\mathrm{MBH})$ of sheep during long- $(\mathrm{LD})$ and short-day $(\mathrm{SD})$ photoperiods. SOCS-3 expression was stimulated $(P<0 \cdot 001)$ by leptin during LD but not SD. * and ${ }^{* *}$ denote differences from controls $(P<0 \cdot 05, P<0 \cdot 001)$.

(Chemineau et al. 2002). After collecting pineal glands from ewes for a separate in vitro experiment, we noted some differences in the size and weight of the pineal glands between sheep. Weight of pineal glands ranged from 60 to $150 \mathrm{mg}$ (mean $87.5 \mathrm{mg}$ ) during LD and from 50 to $113 \mathrm{mg}$ (mean $77.5 \mathrm{mg}$ ) during SD (Zieba et al. unpublished observations). Although the seasonal means in that study did not differ statistically, perhaps due to the small number of samples, it remains possible that individual variability in pineal size contributed to the major differences observed between the two seasons in the present study.

Current studies focused on the ability ofleptin to differentially regulate PRL and melatonin secretion during two seasons in intact females without regard to inherent mechanisms modulating those responses, including changes in circulating ovarian steroids. While it could be argued that the mechanistic features associated with leptin-mediated changes would have been better delineated using ovariectomized, steroid-replaced ewes, a study of those features were beyond the scope of the current work. However, we do not believe that the marked differences in seasonal responses to leptin noted in the current experiments could be accounted for by the changes in circulating estradiol, progesterone, or other ovarian factors. Nonetheless, future work using ovariectomized, steroid-replaced ewes are clearly warranted in order to determine the modulatory effects of both the estrogens and progesterone.

A circadian relationship between melatonin and leptin concentrations was reported earlier by Gündüz (2002) who suggested that photoperiod/melatonin influences the amount of circulating leptin in Siberian hamsters and that these circadian changes in leptin concentrations may be inversely linked to circulating melatonin concentrations. The mechanism of that phenomenon is not clear, but it might be due to melatonin's inhibitory effect on leptin secretion at the level of adipose cells that express melatonin receptors (Zalatan et al. 2001). Furthermore, receptors for melatonin have been localized in the suprachiasmatic nucleus (SCN), dorsomedial nucleus (DMN), and anterior hypothalamic area, but not in the ARC in seasonal species (Morgan \& Mercer 1994). The latter would theoretically rule out the possibility of direct effects of melatonin on leptin signaling within ARC, the primary site of LRs in brain. Co-localization of receptors elsewhere has not yet been demonstrated; however, both melatonin and LRs have been independently localized in the DMN. Morgan et al. (2003) reported that neurons from $\mathrm{DMN}, \mathrm{SCN}$, and $\mathrm{ARC}$ project to the paraventricular nucleus (PVN). Adam \& Mercer (2004) proposed that melatonin could contribute to hypothalamic sensitivity to leptin, acting at the region of the PVN (the center of appetite regulation), a site at which melatonin and leptin feedback may thereby be coordinated.

In another previous report in sheep, Adam et al. (2003) observed that a single, pharmacological i.c.v. dose of leptin specifically stimulated the frequency of luteinizing hormone (LH) pulses and simultaneously decreased appetite in the late autumn. To the contrary, no effect was observed when leptin was applied to the same sheep in the spring. However, the latest results of that group (Adam et al. 2006) do not support the hypothesis that leptin stimulates the reproductive neuroendocrine axis under the influence of photoperiod; however, photoperiod modulates intrahypothalamic leptin sensitivity of appetite. These observations in sheep concerning voluntary feed intake and lack of effects on gonadotrophin-releasing hormone/LH (GnRH/LH) system are consistent with similar studies in the Siberian hamster, which are resistant to leptin during LD but become responsive to leptin treatment in terms of body weight and abdominal fat loss during SD (Atcha et al. 2000). Relative leptin insensitivity during LD may be necessary

$$
\begin{array}{lllllllllllllllllllll}
M & 1 & 2 & 3 & 4 & 5 & 6 & 7 & 8 & 9 & 10 & 11 & 12 & 13 & 14 & 15 & 16 & 17 & 18 & 19 & 20
\end{array}
$$

\footnotetext{
$68 \mathrm{bp}$

SOCS-3

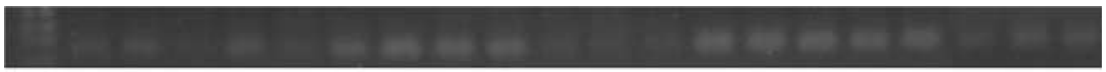

$64 \mathrm{bp}$ Cyclophiline

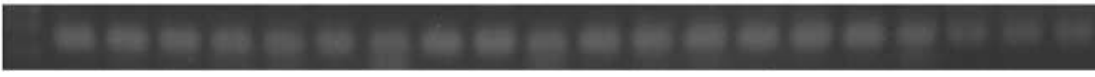

Figure 8 Representative agarose gel of mRNA SOCS-3 expression in medial basal hypothalamus (MBH) of ewes during short- (SD) and long-day (LD) photoperiod (top) relative to the cyclophiline control (bottom). Lanes: $M=$ standard weight marker; 1, 2, 3, 4=Ringer-Locke-treated sheep during LD; 5, 6, 7=leptin low dose (L1 group) LD-treated sheep; 8, 9, 10= leptin high dose (L2 group) LD-treated sheep; 11, 12, 13, 14=Ringer-Locke SD-treated sheep; 15, 16, 17= leptin low dose (L1 group) SD-treated sheep; 18, 19, $20=$ leptin high dose (L2 group) SD-treated sheep.
} 
to prevent the observed increase in leptin concentrations that would cause appetite reduction and, thereby, counteract photoperiod-driven increases in voluntary food intake and body weight (Tups et al. 2004). Collectively, these observations imply that there is a distinct system of regulation in which normal responses to leptin and energy deficit are being overridden by photoperiod (Tups et al. 2004).

Our results also demonstrated a dose-related, leptin-mediated stimulation of PRL release during LD. This observation is consonant with observations of Accorsi et al. (2007) who noted a leptin-mediated enhancement of PRL release in bovine adenohypophyseal explants in culture, although Nonaka $e t$ al. (2007) reported little effect of leptin on PRL release from primary cultures of porcine anterior pituitary cells. Interestingly, Tipsmark et al. (2008) have shown that leptin is a very potent PRL secretagogue in teleost pituitary cultures. Secretion of PRL is tightly connected to melatonin release by the pineal gland, which is a key step in integrating the annual change in day length. In this regard, melatonin has been shown to act within the pars tuberalis (Lincoln \& Clarke 1994). Melatonin receptors are highly expressed at this site, which causes the release of tuberalin, a PRL-releasing factor that regulates the synthesis and release of PRL by lactotrophs in the adjacent pars distalis (Morgan 2000). Lincoln et al. (2006) have proposed an intrapituitary communication between the pars tuberalis and the lactotrophs of the pars tuberalis in the regulation of the circannual PRL rhythm. The variation in plasma PRL concentrations throughout the year could also be involved in the photoperiod/melatonin effect on leptin secretion. However, it is not clear whether PRL is directly involved in adipose tissue responses to day length in sheep. Receptors for PRL on adipose tissue have been reported in mice and rats (Ling \& Billing 2001, Brandebourg et al. 2007), and indirect effects could be mediated via secretion of a putative hepatic factor such as synlactin (English et al. 1990). Melatonin has also been shown to act in discrete hypothalamic areas; however, very little is known about the type of cells that are melatonin targets (Adam \& Mercer 2004). That a positive relationship exists in mammals between photoperiod and PRL secretion has been known for many years, including both sheep and cattle (Tucker \& Merkel 1987, Lincoln 1990). Based on the foregoing, it is possible that central infusion of leptin in the current study may have resulted in PRL secretion either by acting directly at the pituitary or through its central modulation of melatonin secretion.

In the present study, we also conducted a preliminary examination of SOCS-3 mRNA expression in the $\mathrm{MBH}$, a region that includes the ARC and is assumed to play an important role in transduction of the leptin signal into a neuronal response (Zieba et al. 2005). The current study revealed differential SOCS-3 expression relative to SD and LD. The importance of photoperiod and melatonin in the regulation of hypothalamic leptin sensitivity in seasonal animals was demonstrated by Rousseau et al. (2002). In that study, hypothalamic responses to leptin in hamsters were induced primarily by photoperiod. Disinhibition of leptin signaling, represented by lower SOCS-3 mRNA expression during SD, has been implicated in the anorectic action of leptin in that season (Klingenspor et al. 2000). In the current study, we observed a dose-dependent increase in the expression of the SOCS-3 gene in MBH during LD. The relationship of leptin sensitivity to SOCS-3 expression in MBH has been studied most extensively in seasonal animals such as the hamster (Phodopus sungorus; Klingenspor et al. 2000, Mercer et al. 2000). Data of Tups et al. (2006) provided evidence for SOCS-3, not only as a modulator of seasonal changes in leptin signaling, but also as a critical molecular factor in driving and timing the programmed seasonal body weight cycle. Seasonal alternations in SOCS-3 gene expression are independent of reproductive background and are primarily induced by photoperiod (Tups et al. 2006).

Suppressor of cytokine signaling-3 gene expression can also be induced by other photoperiodic hormones that activate signaling pathways through intracellular SOCS-3. PRL, a class I cytokine, whose action can be initiated by hormone-induced receptor homodimerization, activates receptor associated Janus kinase 2 (JAK-2) (Ling \& Billing 2001). This provides a binding site for SOCS-3, which is subsequently phosphorylated by JAK-2. Activated SOCS-3 molecules then dimerize and translocate to the nucleus where they regulate the transcription of several genes and act in a feedback loop to inhibit the action of PRL (Ling \& Billing 2001). However, further work would be required to clarify the possibility of photoperiodic-dependent SOCS-3 activation via PRL.

Taken together, our experiments have provided in vivo evidence that, in seasonal breeding sheep, responses to leptin are associated with photoperiod-driven changes in intrahypothalamic expression of mRNA SOCS-3 in the $\mathrm{MBH}$. These changes were associated with leptin-mediated actions that resulted in differential regulation of both melatonin and PRL secretion during LD and SD. However, additional studies are required to determine whether the changes observed for SOCS-3 signaling are directly related to the control of melatonin or PRL secretion.

\section{Declaration of Interest}

The authors declare that there is no conflict of interest that would prejudice the impartiality of this scientific work.

\section{Funding}

This work was supported by a grant from the Polish National Research Council (KBN 2PO6D 003 29).

\section{Acknowledgements}

We also acknowledge the technical assistance of Dr Jozef Rutkowski and Prof. Edward Wierzchos. 


\section{References}

Accorsi PA, Munno A, Gamberoni M, Viggiani R, De Ambrogi M, Tamanini C \& Seren E 2007 Role of leptin on growth hormone and prolactin secretion by bovine pituitary explants. Journal of Dairy Science 90 1683-1691.

Adam CJ \& Mercer JG 2004 Appetite regulation and seasonality: implications for obesity. Proceedings of the Nutrition Society 63 413-419.

Adam CL, Archer ZA \& Miller DW 2003 Leptin actions on the reproductive neuroendocrine axis in sheep. Reproduction 61 (Suppl 1) 283-297.

Adam CJ, Findlay PA \& Miller DW 2006 Blood-brain leptin transport and appetite and reproductive neuroendocrine responses to intracerebroventricular leptin injection in sheep: influence of photoperiod. Endocrinology 147 4589-4598.

Amstalden M, Garcia MR, Stanko RL, Niezielski SE, Morrison CD, Keisler DH \& Williams GL 2002 Central infusion of recombinant ovine leptin normalized plasma insulin and stimulates a novel hypersecretion of luteinizing hormone after short-term fasting in mature beef cows. Endocrinology 66 1555-1561.

Atcha Z, Cagampang FR, Stirland JA, Morris ID, Brooks AN, Ebling FJ, Klingenspor M \& Loudon AS 2000 Leptin acts on metabolism in a photoperiod-dependent manner, but has no effect on reproductive function in the seasonally breeding Siberian hamster (Phodopus sungurus). Endocrinology $1414128-4135$.

Brandebourg T, Hugo E \& Ben-Jonathan N 2007 Adipocyte prolactin: regulation of release and putative functions. Diabetes, Obesity and Metabolism 4 464-476.

Chemineau P, Daveau A, Bodin L, Zarazaga L, Gomez-Brunet A \& Malpaux B 2002 Sheep as a mammalian model of genetic variability in melatonin. Reproduction 59 181-190.

Clarke IJ, Tilbrook AJ, Tumer AI, Doughton BW \& Goding JW 2001 Sex, fat and the tilt of the earth: effects of sex and season on the feeding response to centrally administered leptin in sheep. Endocrinology 142 2725-2728.

Coon SL, Zarazaga LA, Malpaux B, Ravault JP, Bodin L, Voisin P, Weller JL, Klein DC \& Chemineau P 1999 Genetic variability in plasma melatonin in sheep is due to pineal weight, not to variations in enzyme activities. American Journal of Physiology 227 E972-E977.

Delavaud D, Bocquier F, Chilliard Y, Keisler DH, Gertler A \& Kann G 2000 Plasma leptin in ruminants: effects of nutritional status and body fatness on plasma leptin concentration assessed by a specific RIA in sheep. Journal of Endocrinology 165 519-526.

English DE, Russel SM, Kartz LS \& Nicoll CS 1990 Evidence for a role of the liver in the mammotropic action of prolactin. Endocrinology 118 695-700.

Fraser S, Cowen P, Franklin M, Francy C \& Arendt J 1983 Direct radioimmunoassay for plasma melatonin. Clinical Chemistry 29 386-397.

Gündűz B 2002 Daily rhythm in serum melatonin and leptin levels in the Syrian hamster (Mesocricetus aureatus). Comparative Biochemistry and Physiology 132 393-4021.

Klingenspor M, Dickopp A, Heldemaier G \& Klaus S 1996 Short photoperiod reduces leptin gene expression in white and brown adipose tissue of Djungarian hamsters. FEBS Letters 399 290-294.

Klingenspor M, Niggemann H \& Heldmaier G 2000 Modulation of leptin sensitivity by short photoperiod acclimation in the Djungarian hamster, Phodopus sungorus. Journal of Comparative Physiology B 170 37-43.

Levin BE, Dunn-Meynell AA \& Banks WA 2004 Obesity-prone rats have normal blood-brain barrier transport but defective central leptin signaling before obesity onset. American Journal of Physiology 286 143-150.

Lincoln GA 1990 Correlation with changes in horns and pelage, but not reproduction, of seasonal cycles in the secretion of prolactin in rams of wild, feral and domesticated breeds of sheep. Journal of Reproduction and Fertility 90 285-296.

Lincoln GA \& Clarke IJ 1994 Photoperiodically-induced cycles in the secretion of prolactin in the hypothalamo-pituitary disconnected rams: evidence for translation of the melatonin signal in the pituitary gland. Journal of Neuroendocrinology 6 251-260.

Lincoln GA, Clarke IJ, Hut RA \& Hazlerigg DG 2006 Characterizing a mammalian circannual pacemaker. Science 314 1941-1943.
Ling C \& Billing H 2001 PRL receptor-mediated effects in female mouse adipocytes: PRL induces suppressors of cytokine signaling expression and suppresses insulin-induced leptin production in adipocytes in vitro. Endocrinology 142 4880-4890.

Mercer JG, Moar KM, Ross AW, Hoggard N \& Morgan PJ 2000 Photoperiod regulates acruate nucleus POMC, AGRR, and leptin receptor mRNA in Siberian hamster hypothalamus. American Journal of Physiology $\mathbf{2 7 8}$ R271-R281.

Misztal T, Romanowicz K \& Barcikowski B 1996 Seasonal changes of melatonin secretion in relation to the reproductive cycle in sheep. Journal of Animal and Feed Sciences 56 35-48.

Morgan PJ 2000 The pars tuberlis: the missing link in the photoperiodic regulation of prolactin secretion? Journal of Neuroendocrinology 12 287-295.

Morgan PJ \& Mercer JG 1994 Contril of seasonality by melatonin. Proceedings of the Nutrition Society $\mathbf{5 3}$ 483-493.

Morgan PJ, Ross AW, Mercer JG \& Barrett P 2003 Photoperiodic programming of body weight through the neuroendocrine hypothalamus. Journal of Endocrinology 177 27-34.

Münzberg H, Bjonholm M, Bates H \& Meyers MG 2005 Leptin receptor action and mechanism of leptin resistance. Cellular and Molecular Life Sciences 62 642-652.

Nonaka S, Hashizume T \& Yamashita T 2007 Effects of leptin and leptin peptide amine on the release of luteinizing hormone, growth hormone and prolactin form cultured porcine anterior pituitary cells. Animal Science Journal 77 47-52.

Norms 1993 Nutrient requirements for cattle and sheep in the traditional system (in Polish). IZ Krakow, Poland.

Rousseau K, Atcha Z, Cagampang FR, Le Rouzic P, Stirland JA, Ivanov TR, Ebling FJ, Kilngenspor M \& Loudon AS 2002 Photoperiodic regulation of leptin resistance in the seasonally breeding Siberian hamster (Phodopus sungorus). Endocrinology 143 3083-3095.

Russel AJP, Doney JM \& Gunn RG 1969 Subjective assessment of body fat in live sheep. Journal of Agricultural Science 72 451-454.

Symonds ME \& Clarke L 1998 Influence of maternal bodyweight on adaptation after birth in near-term lambs delivered by Caesarean section. Reproduction, Fertility, and Development 10 333-339.

Tipsmark CK, Strom CN, Bailey ST \& Borski RJ 2008 Leptin stimulates pituitary prolactin release through an extracellular signal-regulated protein kinase (ERK) dependent pathway. Journal of Endocrinology 196 275-281.

Traczyk W \& Przekop F 1963 Methods of investigation of the function of the hypothalamus and hypophysis in chronic experiment in sheep. Acta Physiologica Polonica 14 217-226.

Tucker HA \& Merkel RA 1987 Applications of hormones in the metabolic regulation of growth and lactation in ruminants. Federation Proceedings $\mathbf{4 6}$ 300-306.

Tups A, Ellis C, Moar KM, Logie TJ, Adam CL, Mercer JG \& Klingenspor M 2004 Photoperiodic regulation of leptin sensitivity in the Siberian hamster, Phodopus sungorus, is reflected in arcuate nucleus SOCS-3 (suppressor of cytokine signaling) gene expression. Endocrinology 145 1185-1193.

Tups A, Barrett P, Ross AW, Morgan PJ, Klingenspor M \& Mercer G 2006 The suppressor of cytokine signaling 3 , SOCS3, may be one critical modulator of seasonal body weight changes in the Siberian hamster, Phodopus sungorus. Journal of Neuroendocrinology 18 139-145.

Watanobe H \& Habu S 2002 Leptin regulates growth hormone-releasing factor, somatostatin, and alpha-melanocyte-stimulating hormone but not neuropeptide $\mathrm{Y}$ release in rat hypothalamus in vivo: relation with growth hormone secretion. Endocrinology 139 3871-3875.

Wolinska E, Polkowska J \& Domanski E 1977 The hypothalamic centers involved in the control of production and release of prolactin in sheep. Journal of Endocrinology 73 21-29.

Zalatan F, Krause JA \& Blask DE 2001 Inhibition of isoproterenol-induced lipolysis in rat linguinal adipocytes in vitro by physiological melatonin via a receptor-mediated mechanism. Endocrinology 142 3783-3790.

Zieba DA, Amstalden M, Maciel MN, Keisler DH, Raver N, Gertler A \& Williams GL 2003a Divergent effects of leptin on luteinizing hormone and insulin secretion are dose dependent. Experimental Biology and Medicine 228 $325-330$ 
Zieba DA, Amstalden M, Morton S, Gallino JL, Edwards JF, Harms PG \& Williams GL 2003b Effects of leptin on basal and GHRH-stimulated GH secretion from the bovine adenohypophysis are dependent upon nutritional status. Journal of Endocrinology 178 83-89.

Zieba DA, Amstalden M, Morton M, Keisler DH \& Williams GL 2004 Regulatory roles of leptin at the hypothalamic-hypophyseal axis before and after sexual maturation in cattle. Biology of Reproduction $\mathbf{7 1}$ 804-812.

Zieba DA, Amstalden M \& Williams GL 2005 Regulatory roles of leptin in reproduction and metabolism in cattle. Domestic Animal Endocrinology 29 $166-185$
Zieba DA, Klocek B, Williams GL, Romanowicz K, Boliglowa L \& Wozniak M 2007 In vitro evidence that leptin suppresses melatonin secretion during long days and stimulates its secretion during short days in seasonal breeding ewes. Domestic Animal Endocrinology 33 358-365.

Received in final form 23 April 2008

Accepted 29 April 2008

Made available online as an Accepted Preprint 30 April 2008 